\title{
Improvement in Magnetic Properties of PLD-Made Nd-Fe-B Thick Film Magnets
}

\author{
M. Nakano ${ }^{1}$, H. Takeda ${ }^{1}$, F. Yamashita ${ }^{2}$, T. Yanai ${ }^{1}$, and H. Fukunaga ${ }^{1}$ \\ ${ }^{1}$ Department of Electrical and Electronic Engineering, Nagasaki University, Nagasaki 852-8521, Japan \\ ${ }^{2}$ Motor Technology Center, Matsushita Electric Industrial Co., Osaka 574-0044, Japan
}

\begin{abstract}
Coercivity of pulsed laser deposition (PLD)-fabricated Nd-Fe-B thick film magnets were enhanced by synergistic use of an additive (Zr, $\mathrm{Nb}$ or Ga) and an adoption of pulse annealing as a high-speed crystallization method. The role of the additives and the pulse annealing mainly work on the increase of coercivity without the deterioration of remanence and $(B H)_{\max }$. For example, after pulse annealing of an as-deposited film prepared from a $\mathrm{Nd}_{2.6} \mathrm{Fe}_{14} \mathrm{~B}+\mathrm{Ga}_{0.5}$ at.\% target, the obtained coercivity reached approximately $1700 \mathrm{kA} / \mathrm{m}$. We also found that $(B H)_{\max }$ value reaches approximately $70 \mathrm{~kJ} / \mathrm{m}^{3}$ by reducing $\mathrm{Nd}$ content and adding $\mathrm{Zr}$ or $\mathrm{Nb}$.
\end{abstract}

Index Terms-Coercivity, pulsed laser deposition, remanence, thick film magnets.

\section{INTRODUCTION}

W E have already reported the fabrication of isotropic Nd-Fe-B thick film magnets, which have coercivity, remanence, and $(B H)_{\max }$ values of approximately $1000 \mathrm{kA} / \mathrm{m}$, $0.6 \mathrm{~T}$, and $60 \mathrm{~kJ} / \mathrm{m}^{3}$, respectively, prepared by the PLD method with a high deposition rate of approximately $90 \mu \mathrm{m} / \mathrm{h}$ [1]. In addition, an application of a $200 \mu \mathrm{m}$-thick Nd-Fe-B film on a Fe substrate to a milli-size motor was carried out as a practical usage, and it was confirmed that the rotation speed and torque constant under no-load test are $15160 \mathrm{rpm}$ and $0.0236 \mathrm{mNm} / \mathrm{A}$, respectively, at the gap of $0.1 \mathrm{~mm}$ between a rotor and a stator. As the advancement in micro-machines such as small motors depends on magnetic properties of small size magnets, a further improvement in magnetic properties of film magnets is strongly required.

According to the observation on microstructure for the previously reported films [2], the size of $\mathrm{Nd}_{2} \mathrm{Fe}_{14} \mathrm{~B}$ grains ranged widely from 5 to $440 \mathrm{~nm}$, and the average grain size was estimated at $150 \mathrm{~nm}$, which suggests that refinement in grain size is a key technology to improve magnetic properties of the thick film magnets. It has also been reported that a use of additives such as $\mathrm{Zr}, \mathrm{Nb}, \mathrm{Ga}$ is effective to obtain homogeneous microstructure, and resultantly to increase remanence and coercivity for Nd-Fe-B based ribbons and HDDR powder [3]-[5], respectively.

This contribution reports magnetic properties of the PLD-fabricated thick films prepared from Nd-Fe-B targets including $\mathrm{Zr}$, $\mathrm{Nb}, \mathrm{Ga}$ additives. Furthermore, the pulse annealing as a highspeed crystallization method was applied to the films including the additives.

\section{EXPERIMENTAL}

The targets with the composition of $\mathrm{Nd}_{2.4} \mathrm{Fe}_{14} \mathrm{~B}$, $\mathrm{Nd}_{2.6} \mathrm{Fe}_{14} \mathrm{~B}+\mathrm{M}_{0.5}$ at.\% $(\mathrm{M}=\mathrm{Zr}, \mathrm{Nb}, \mathrm{Ga})$ and $\mathrm{Nd}_{2.0} \mathrm{Fe}_{14} \mathrm{~B}+$ $\mathrm{M}_{0.5}$ at.\% $(\mathrm{M}=\mathrm{Zr}, \mathrm{Nb}, \mathrm{Ga})$ were prepared. They were ablated with a Nd-YAG pulse laser $(\lambda=355 \mathrm{~nm})$ at the repetition rate

Digital Object Identifier 10.1109/TMAG.2008.2001492

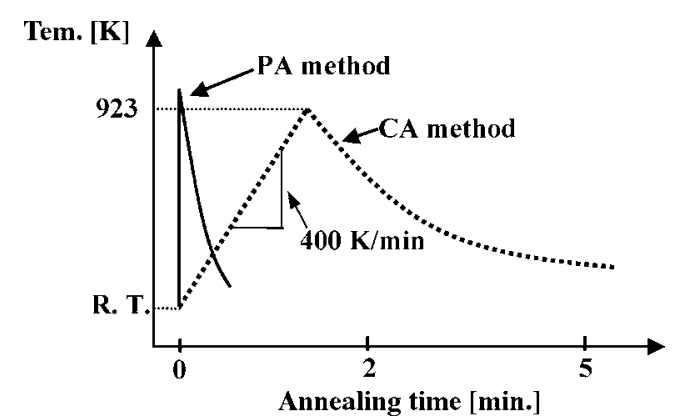

Fig. 1. Schematic diagram of CA and PA methods.

of $30 \mathrm{~Hz}$, and the films were deposited on Ta substrates. The distance between a target and a substrate and deposition time were fixed at $10 \mathrm{~mm}$ and $1 \mathrm{~h}$, respectively. In this experiment, the deposition rate was varied from 20 to $40 \mu \mathrm{m} / \mathrm{h}$, and the film thickness ranging was 20 to $40 \mu \mathrm{m}$. Before the ablation, the chamber was evacuated down to approximately $10^{-5} \mathrm{~Pa}$ with a molecular turbo pump. In addition, a Ti sublimation pump was used as an auxiliary pump during the deposition. As-deposited films were amorphous, and, therefore, they were crystallized by annealing with an infrared furnace whose maximum output power was $8 \mathrm{~kW}$. We set the annealing temperature, heating rate and holding time at $923 \mathrm{~K}, 400 \mathrm{~K} / \mathrm{min}$ and $0 \mathrm{~min}$, respectively, as the conditions of a conventional annealing (CA) method. In addition, we adopted a pulse annealing (PA) method, in which samples were instantaneously crystallized for 1.7-2.0 s as a high-speed crystallization method (see Fig. 1). As shown in Fig. 2, the size of $\mathrm{Nd}_{2} \mathrm{Fe}_{14} \mathrm{~B}$ grains for a sample annealed by PA method was smaller than that of one annealed by CA method [6]. A peeling phenomenon was not observed in all samples which indicated that the mechanical properties of the films prepared by PA method were comparable with those of ones prepared by CA method [7].

After a sample was magnetized up to $7 \mathrm{~T}$ with a pulse magnetizer, magnetic properties were measured with a vibrating sample magnetometer which could apply a magnetic field up to approximately $1800 \mathrm{kA} / \mathrm{m}$ reversibly. All the post-annealed films were magnetically isotropic and, therefore, in-plane magnetic properties were shown in this article. The analysis of crystal structure was carried out with an X-ray diffractometer 


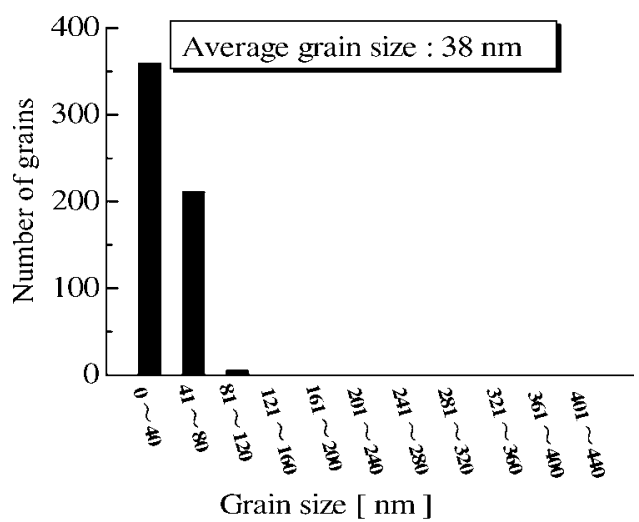

(a)

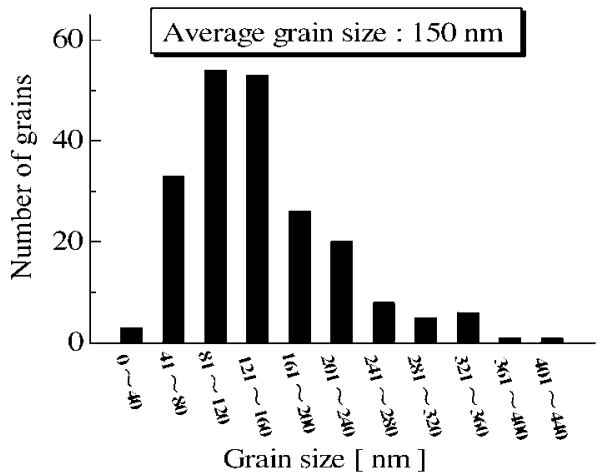

(b)

Fig. 2. Grain size distributions of the samples annealed by PA and CA methods. Average grain diameters of each sample were 40 and $150 \mathrm{~nm}$, respectively. PA method is effective to obtain samples with homogeneous grain size. (a) PA method; (b) CA method.

(XRD) and the average thickness was estimated from hysteresis loops of as-deposited films as described elsewhere [8].

\section{RESUlTS AND DisCUSSION}

As mentioned in Introduction, it has been reported that use of additives is effective to obtain homogeneous structure, and resultantly they improved the magnetic properties of $\mathrm{Nd}-\mathrm{Fe}-\mathrm{B}$ based ribbons and HDDR powder [3]-[5]. In this experiment, we also tried to improve the magnetic properties of the films by using $\mathrm{Zr}$, Nb and Ga. Fig. 3 shows demagnetization curves of PLD-fabricated Nd-Fe-B thick film magnets prepared from $\mathrm{Nd}_{2.6} \mathrm{Fe}_{14} \mathrm{~B}+\mathrm{M}_{0.5}$ at.\% $(\mathrm{M}=\mathrm{Zr}, \mathrm{Nb}, \mathrm{Ga})$ targets followed by $\mathrm{CA}$ method. Use of targets with each additive increased the coercivity by $100-300 \mathrm{kA} / \mathrm{m}$ compared with that of a sample prepared from the additive free target, although it did not affect the remanence and $(B H)_{\max }$ values. Ga was the most effective to enhance the coercivity, and the obtained coercivity of the sample was $1460 \mathrm{kA} / \mathrm{m}$. X-ray diffraction patterns of the above-mentioned samples were shown in Fig. 4. The same peaks originating from the $\mathrm{Nd}_{2} \mathrm{Fe}_{14} \mathrm{~B}$ structure were observed in all the samples and the formation of no different crystalline phases were detected.

For a further increase in coercivity, the PA method together with one of the above-mentioned additives was adopted. Fig. 5 shows the demagnetization curves of PLD-fabricated Nd-Fe-B thick film magnets prepared from $\mathrm{Nd}_{2.6} \mathrm{Fe}_{14} \mathrm{~B}+\mathrm{M}_{0.5}$ at.\% $(\mathrm{M}=\mathrm{Zr}, \mathrm{Nb}, \mathrm{Ga})$ targets followed by the PA method. The role

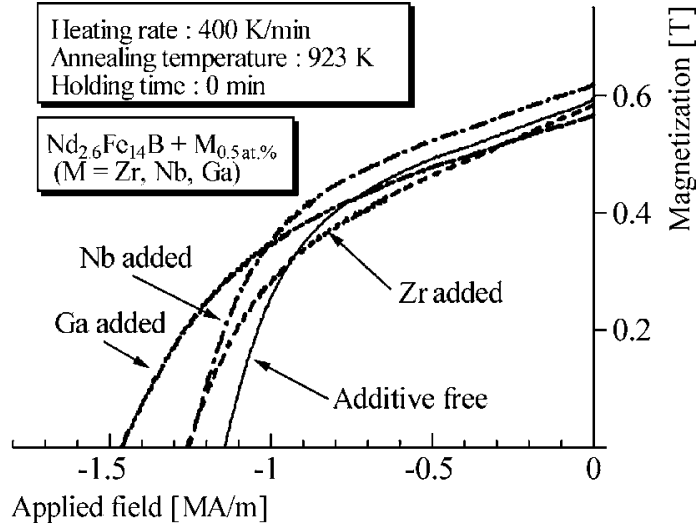

Fig. 3. Demagnetization curves of PLD-fabricated Nd-Fe-B thick film magnets prepared by a conventional annealing (CA) method from $\mathrm{Nd}_{2.6} \mathrm{Fe}_{14} \mathrm{~B}+$ $\mathrm{M}_{0.5}$ at.\% $(\mathrm{M}=\mathrm{Zr}, \mathrm{Nb}, \mathrm{Ga})$ targets. Use of additive of $\mathrm{Zr}, \mathrm{Nb}$ and $\mathrm{Ga}$ enabled us to increase coercivity of the samples by $100-300 \mathrm{kA} / \mathrm{m}$ compared with that of additive free one.

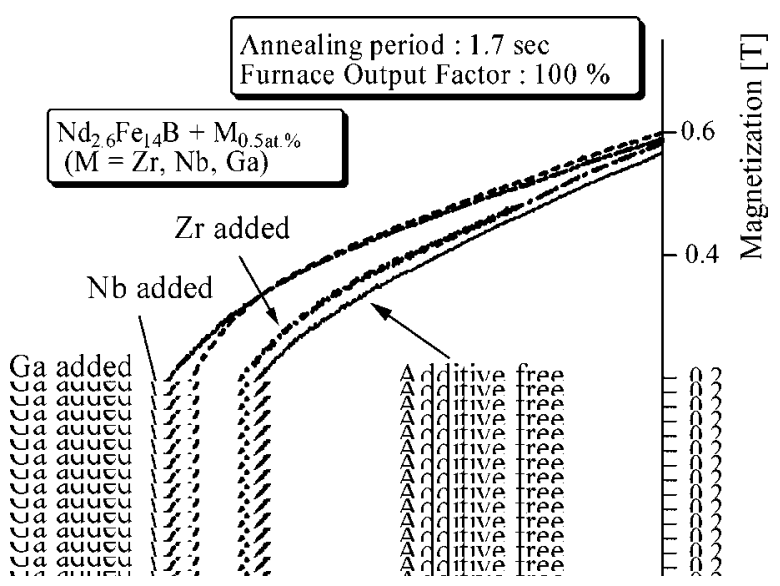

Fig. 4. X-ray diffraction patterns of PLD-fabricated Nd-Fe-B thick film magnets prepared by a conventional annealing (CA) method from $\mathrm{Nd}_{2.6} \mathrm{Fe}_{14} \mathrm{~B}+\mathrm{M}_{0.5 \text { at.\% }}(\mathrm{M}=\mathrm{Zr}, \mathrm{Nb}, \mathrm{Ga})$ targets. The same peaks originating from $\mathrm{Nd}_{2} \mathrm{Fe}_{14} \mathrm{~B}$ structure were observed in all samples.

of the additives and the PA method mainly work on the increase of coercivity. For example, after a pulse annealing of an as-deposited film prepared from a $\mathrm{Nd}_{2.6} \mathrm{Fe}_{14} \mathrm{~B}+\mathrm{Ga}_{0.5}$ at.\% target, the obtained coercivity reached approximately $1700 \mathrm{kA} / \mathrm{m}$. In the previous report for the grain refinement in isotropic $\mathrm{Nd}-\mathrm{Fe}-\mathrm{B}$ ribbons [4], remanence enhancement was reported together with increase in coercivity. Our experiment, however, did not indicate the remanence enhancement, suggesting that the intergrain exchange interaction among $\mathrm{Nd}-\mathrm{Fe}-\mathrm{B}$ grains was ultimately little. On the other hand, it is considered that the enhancement in coercivity is attributed to the increases in numbers of grains with a single domain structure. In Fig. 6, the above-mentioned results were summarized. It was clarified that an adoption of PA method as a high-speed crystallization one together with additives such as Ga showed the synergistic results for the enhancement in coercivity.

As the cooperated effect of the PA method and additives causes a remarkable increase in coercivity, we can reduce the $\mathrm{Nd}$ content of a target. Therefore, we prepared the film magnets from $\mathrm{Nd}_{2.0} \mathrm{Fe}_{14} \mathrm{~B}+\mathrm{M}_{0.5}$ at.\% $(\mathrm{M}=\mathrm{Zr}, \mathrm{Nb}, \mathrm{Ga})$ targets 


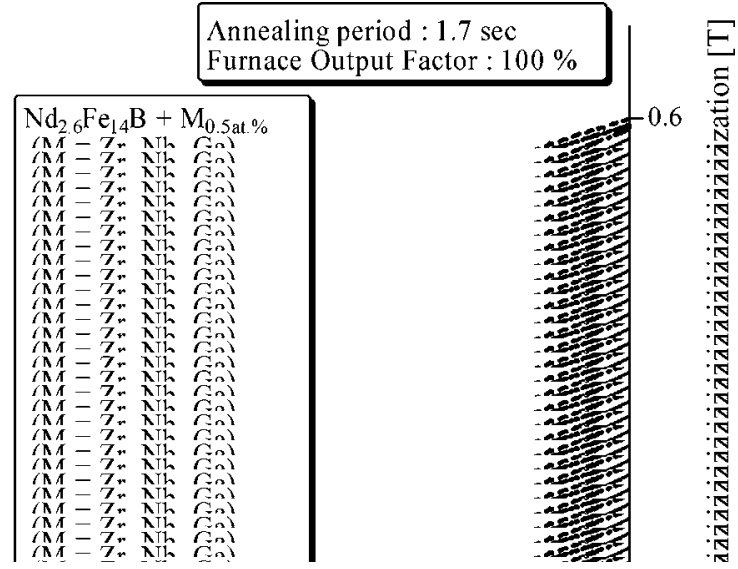

Fig. 5. Demagnetization curves of PLD-fabricated Nd-Fe-B thick film magnets prepared by a pulse annealing (PA) method from $\mathrm{Nd}_{2.6} \mathrm{Fe}_{14} \mathrm{~B}+\mathrm{M}_{0.5}$ at.\% $(\mathrm{M}=\mathrm{Zr}, \mathrm{Nb}, \mathrm{Ga})$ targets. The coercivity of the samples prepared from a $\mathrm{Ga}$ added target was approximately $1700 \mathrm{kA} / \mathrm{m}$.

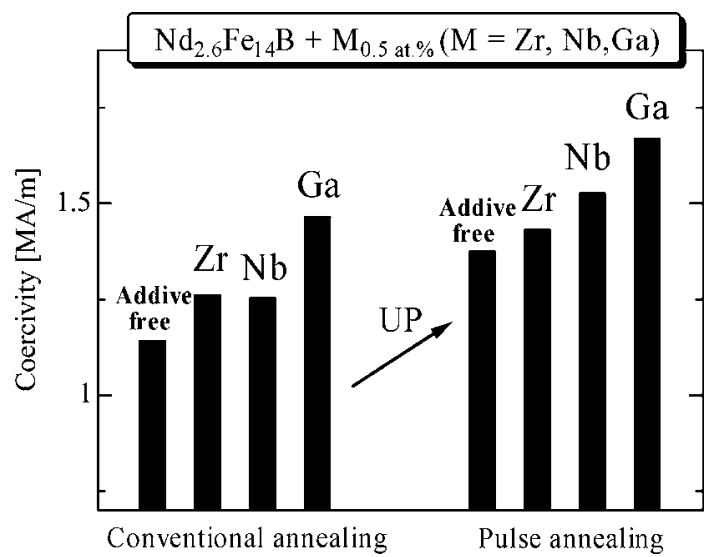

Fig. 6. Comparison of coercivity values for samples prepared by two methods of $\mathrm{CA}$ and PA from $\mathrm{Nd}_{2.6} \mathrm{Fe}_{14} \mathrm{~B}+\mathrm{M}_{0.5}$ at.\% $(\mathrm{M}=\mathrm{Zr}, \mathrm{Nb}, \mathrm{Ga})$ targets. It was clarified that an adoption of PA as a high-speed crystallization method together with additives showed the synergistic results for the enhancement in coercivity.

followed by the PA method. The obtained demagnetization curves are shown in Fig. 7. An increase in remanence by approximately $0.1 \mathrm{~T}$ could be achieved compared with those of samples prepared from $\mathrm{Nd}_{2.6} \mathrm{Fe}_{14} \mathrm{~B}+\mathrm{M}_{0.5}$ at.\% $(\mathrm{M}=\mathrm{Zr}, \mathrm{Nb}$, $\mathrm{Ga}$ ) targets. It was also found that an addition of $\mathrm{Zr}, \mathrm{Nb}$ and $\mathrm{Ga}$ is effective to increase the coercivity for the targets with stoichiometric composition. Resultantly, an enhancement in $(B H)_{\max }$ was successfully achieved and obtained $(B H)_{\max }$ value reached approximately $70 \mathrm{~kJ} / \mathrm{m}^{3}$ for the both of $\mathrm{Zr}$ and $\mathrm{Nb}$ added films.

\section{CONCLUSION}

The relationship between magnetic properties and the additives such as $\mathrm{Zr}, \mathrm{Nb}$ and $\mathrm{Ga}$ was investigated for PLD- fabricated $\mathrm{Nd}-\mathrm{Fe}-\mathrm{B}$ thick film magnets, and it was clarified that the role of additives mainly works on the coercivity enhancement without the deterioration of remanence and $(\mathrm{BH})_{\max }$. For example, an increase in coercivity of a film including Ga additive by adopting a pulse annealing method enables us to obtain

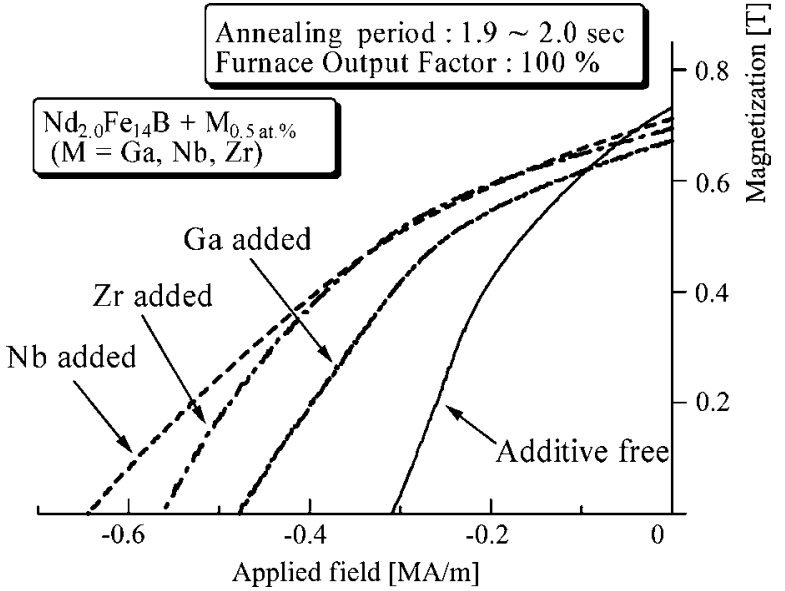

Fig. 7. Demagnetization curves of PLD-fabricated Nd-Fe-B thick film magnets prepared by a pulse annealing (PA) method from $\mathrm{Nd}_{2.0} \mathrm{Fe}_{14} \mathrm{~B}+\mathrm{M}_{0.5}$ at.\% $(\mathrm{M}=\mathrm{Zr}, \mathrm{Nb}, \mathrm{Ga})$ targets. $(B H)_{\max }$ value reached approximately $70 \mathrm{~kJ} / \mathrm{m}^{3}$ by reducing $\mathrm{Nd}$ content and add $\mathrm{Zr}$ or $\mathrm{Nb}$.

approximately $1700 \mathrm{kA} / \mathrm{m}$. We also found that $(\mathrm{BH})_{\max }$ value reaches approximately $70 \mathrm{~kJ} / \mathrm{m}^{3}$ by reducing $\mathrm{Nd}$ content and add $\mathrm{Zr}$ or $\mathrm{Nb}$.

\section{ACKNOWLEDGMENT}

This work was supported in part by the Ministry of Education, Science, Sports and Culture of Japan under a Grand-in-Aids (19360147 and 10136533) and the energy use rationalization technology and strategy developments program in 2005 from New Energy and Industrial Technology Development Organization (NEDO, Project P03033) of Japan.

\section{REFERENCES}

[1] M. Nakano, F. Yamashita, T. Honda, J. Yamasaki, K. Ishiyama, J. Fidler, T. Yanai, and H. Fukunaga, "Review of fabrication and characterization of Nd-Fe-B thick films for magnetic micromachines," IEEE Trans. Magn., vol. 43, no. 6, pp. 2672-2676, Jun. 2007

[2] M. Nakano, R. Kato, S. Hoefinger, J. Fidler, F. Yamashita, and H. Fukunaga, "Microstructure and magnetic properties of PLD-made Nd-Fe-B thick films," J. Alloys Compd., vol. 408-412, pp. 1422-1425, 2006.

[3] H. Hashino, Y. Tazaki, H. Ino, T. Ohkubo, and K. Hono, "Effect of Zr and $\mathrm{C}$ additions on the magnetic properties and structures of melt-spun $\mathrm{Fe}_{83} \mathrm{Nd}_{10} \mathrm{~B}_{7}$-based nanocomposite magnets," J. Magn. Magn. Mater., vol. 278 , pp. $68-75,2004$.

[4] Z. Chen, Y. Q. Wu, M. J. Kramer, B. R. Smith, B. M. Ma, and M. Huang, "A study on the role of $\mathrm{Nb}$ in melt-spun nanocrystalline Nd-Fe-B magnets," J. Magn. Magn. Mater., vol. 268, pp. 105-113, 2004.

[5] S. Sugimoto, H. Murai, N. Koike, D. Book, N. Tezuka, T. Kagotani, M. Okada, M. Oakada, M. Homma, and K. Inomata, "Improvement of coercivity of anisotropic Nd-Fe-B HDDR powders by Ga addition," $J$. Magn. Magn. Mater., vol. 239, pp. 444-446, 2002.

[6] M. Nakano, H. Takeda, S. Sato, T. Yanai, F. Yamashita, and H. Fukunaga, J. Appl. Phys., vol. 101, pp. 09K525-1-09K525-3, 2007.

[7] M. Nakano, T. Honda, J. Yamasaki, S. Sato, J. Fidler, and H. Fukunaga, Sensor Lett., vol. 5, pp. 48-50, 2007.

[8] M. Nakano, S. Tsutsumi, and H. Fukunaga, "Magnetic properties of Nd-Fe-B thick-film magnets prepared by laser ablation technique," IEEE Trans. Magn., vol. 38, no. 5, pp. 2913-2915, Sep. 2002.

Manuscript received March 02, 2008. Current version published December 17, 2008. Corresponding author: M. M. Nakano (e-mail: mnakano@nagasaki-u.ac.jp). 